\title{
Improving the quality of social work field education: The efficacy of an analysis using Cultural-Historical Activity Theory
}

\author{
Dominic Chilvers
}

Dominic Chilvers is a social work lecturer and coordinates the field education programme at Christchurch Polytechnic Institute of Technology. He was previously the Executive Officer of ANZASW and before that gained 10 years' practice experience in both England and Aotearoa New Zealand. Dominic Chilvers: dominic.chilvers@cpit.ac.nz.

\begin{abstract}
Field education is recognised as a critical element in the preparation of social workers for competent practice. It is also acknowledged as a major pressure point in the provision of social work education in Aotearoa New Zealand. The pressures appear to be related to concerns about quality, consistent standards and the preparation of field educators who often lack the confidence or specialised knowledge and pedagogical skills required to facilitate student learning in the field. Attempts to address these concerns have generally focused on either local or national training programmes based on traditional learning theories. This article proposes that Cultural-Historical Activity Theory offers an alternative approach to the challenge of quality in field education and provides a basic description of the model. In particular, the analytical tools developed by Yrjö Engeström, which focus on the exploitation of tensions and contradictions in activity systems, are discussed as a useful strategy to bring about transformation. The article suggests that Cultural-Historical Activity Theory has been underutilised in social work research, but has the potential to open up rich veins of enquiry related to a range of concerns.
\end{abstract}

\section{Introduction}

Social work students report that the field placement is the most significant single component of their professional education (Fortune \& Abramson, 1993). This finding should present a significant challenge to social work educators and practitioners alike; how to collaborate to ensure the quality and effectiveness of field education. A failure in this aspect of professional education is likely to have significant implications for the future of the profession. Field education is a critical interface, the point at which educators and practitioners, academic institutions and social service agencies must collaborate towards a common goal. Equally critical, it provides an experience that has a lasting impact on the neophyte social worker's approach to practice, either positive or negative.

In a recent survey of social work educators in Aotearoa New Zealand, conducted by the Tertiary Education Commission (2009), survey participants indicated concern for the quality 
of field education, particularly in the non government organisation (NGO) sector. This finding is concerning since the survey also highlighted the growing demand for field placements, and indicated that NGOs currently provide a very significant proportion of practicums (43\%). The TEC report concluded that field education is a major pressure point for the social work profession in Aotearoa New Zealand and suggested that common standards are required across education providers, particularly in the area of training field educators.

If the social work profession is to respond to the challenge of ensuring efficacy in field education, clearly field educators need to be well prepared for their critical role. It is therefore important to understand the factors that influence how social workers learn to become field educators and the developmental processes that can be used to improve outcomes for students. This article explores the potential for using Cultural-Historical Activity Theory to assist in the development of this area of knowledge.

\section{Pedagogy and field education}

Student social workers require more from field education than simply an opportunity to shadow experienced practitioners or to learn task-oriented skills associated with a specific social service setting (Shardlow \& Doel, 1996; Vayda and Bogo, 1991). Undertaking social work tasks must be complemented by activities focused on teaching and learning (Fortune \& Abramson, 1993). A number of research studies have revealed the methods that students identify as important for field educators to employ to create a successful placement. Knight (1996) found that encouraging open discussion of concerns and explaining purpose and role were particularly important. Other positively regarded methods include structured orientation, one-to-one supervision, observing other social workers' practice, discussion of case notes, and self critique (Fernandez, 1998; Fortune, McCarthy, \& Abramson, 2001; Maidment, 2000). It could be argued that these methods might be familiar to experienced social workers but others are perhaps less so, and are therefore at risk of being used less frequently. Although students and field educators agree that direct observation of the student, use of one-way screens, co-working with the student, audio or video recordings, role play, student presentations, and process recordings are very effective methods to promote learning in the placement, evidence suggests that these methods are actually underutilised (Fortune et al., 2001; Maidment, 2000; Wilson, Walsh \& Kirby, 2008). Knight (1996) also found that some field educators fail to help students learn how to integrate theory and practice. These findings suggest that field educators may underutilise certain teaching methods that are necessary to support effective student learning due to a lack of professional confidence.

It therefore seems clear from previous research that the educational skills required of a field educator are not necessarily innate or naturally developed through learning to be a competent social worker. Social workers who become field educators are likely to require new competencies that originate from an adult education discourse with which they are probably unfamiliar. Practitioners inhabit an environment largely disconnected from the culture and history of adult education and therefore many of the motivators to become a proficient educator are absent. Even participation as a field educator does not necessarily lead to extensive contact with other educators in an academic environment. It is therefore critical that field educators expand their learning to incorporate the knowledge, skills and attitudes of an educator, so that they can effectively support student learning in the context of a field placement. 


\section{Field educator training}

Concerns for the quality of field education and the need for field educators to develop specialist competencies have led to the development of specialised training in a number of locations. Many education providers have developed their own courses for field educators, some making these a pre-requisite for working with students. For example, Fernandez (2003) describes a 35-hour course developed at the University of New South Wales. Her evaluation of the course indicates that participants felt they gained a greater understanding of the nature and importance of field education, learnt new conceptual frameworks for teaching and learning, clarified their relationship to the educational institution and felt more able to assume the role of an educator. Although these findings are encouraging, Fernandez did not explore whether there was a link between this training and the quality of field instruction later provided by participants. We are therefore left uncertain about whether trained field educators are actually better at helping students learn in the context of their practicum, although one might intuitively anticipate this to be the case.

In contrast to this type of institution-specific response, an industry-wide approach was undertaken in the UK in the early 1990s in response to the same concerns about the quality of field education and the competence of field educators (Bellinger, 2010). The Practice Teaching Award was developed by the Central Council for Education and Training in Social Work, and a robust system of audit and review established. Central government funding was provided to support the infrastructure requirements and providers were paid for each candidate that enrolled. Bellinger paints a picture of this being a golden era for field education and a period in which the UK became the class leader. However, this was clearly a resource-intensive approach and it is perhaps unsurprising that funding pressures began to jeopardise the Practice Teaching Award within a decade of its introduction. Bellinger argues strongly that subtle changes in terminology and standards, along with de-regulation and the de-emphasis of pedagogy have created significant vulnerability in the quality of social work education in the UK. Although it may seem self evident that the solution would be a return to the heady days of a centrally funded and regulated programme of training for field educators, perhaps other solutions to the problems of quality and competence are possible.

\section{Theories about learning}

Both the institution-specific and the industry-wide response to concerns about quality in field education and competence of field educators appear to be based on a fairly traditional conceptualisation of learning. This model views learning as a largely individual process of acquiring propositional knowledge or rules for action, leading to some lasting change in observable behaviour, generally facilitated by a teacher. The work of Russian psychologist Lev Vygotsky suggests an alternate view that emphasises the cultural essence of learning and the socially situated nature of development (van Oers, 2008). From this perspective, learning to be an effective field educator is dependent on the interaction between practitioners with more or less experience and the sharing of cultural tools that are required to be a field educator. This learning process is also profoundly influenced by the social situation in which it takes place. For example, Vygotsky's approach suggests that if a new field educator is provided with the opportunity to work in a supportive team, alongside an experienced practitioner, practising progressively independent use of the teaching resources and assess- 
ment documentation used by their experienced colleague, then they will swiftly develop competence as a field educator.

Lave and Wenger (1991) have used Vygotsky's ideas in the development of a theory of situated learning. They suggest that learning is a social process that involves the learner coming to behave in ways that are considered competent by experienced practitioners. Learning is therefore a process of moving from peripheral to central participation in a community of practice. Lave and Wenger's theory has led to efforts in a wide range of settings to develop communities of practice that efficaciously help members to learn the skills required in that context. Although this theory is helpful in expanding the concept of learning from a purely personal cognitive process, it tends to lead to a one size fits all solution that implies that the development of communities of practice will naturally lead to improved learning. However, this solution downplays the potential inhibiting effect that communities of practice can have on learning and the possibility for individuals to belong to multiple communities that may exert conflicting influence (Fuller, 2007). Billett (2007) has also highlighted the moderating effect that individual agency has on any influence exerted by the community. Therefore, although developing communities of practice in field education may be helpful, this approach risks being a prescriptive solution that fails to address the complex web of factors that influence a practitioner's journey toward excellent competence.

Cultural-Historical Activity Theory (Activity Theory) also originates from Vygotsky's ideas about the cultural nature of learning. However, unlike situated learning, it focuses less on the individual learner and prescriptive solutions, offering a flexible analytical model that encourages collective engagement with the complexities of practice to facilitate the discovery of dynamic solutions to the challenges being encountered in the real world. This approach offers some exciting possibilities to researchers interested in advancing field education.

\section{Unfamiliarity of Cultural-Historical Activity Theory}

Cultural-Historical Activity Theory remained hidden from western researchers for several decades, following its early beginnings at the turn of the 20th century, due to political influence and a general lack of awareness in the west about Russian psychological research. Over the last two decades it has been more widely publicised in the west (Engeström \& Miettinen, 1999) and applied to a range of disciplines; inter alia, organisational development (e.g. Engeström, 2000), education (e.g. Daniels, 2004; Feryok, 2009), and online learning (e.g. Kollias, Mamalougos, Vamvakoussi, Lakkala, \& Vosniadou, 2005; Guldberg, 2010). Key contemporary theorists such as Yrjö Engeström have taken a highly inter-disciplinary approach, and broken out of the constraints of any one academic tradition. However, despite apparent connections with familiar social work theories such as Systems Theory, Activity Theory does not appear to have gained widespread popularity with social work researchers.

A systematic literature review revealed a paucity of social work studies that have used an Activity Theory perspective, although some social work researchers have used it to good effect. For example, Edwards (2007) used Activity Theory as an explanatory model in her work focused on social exclusion in England. Leadbetter (2008) used Activity Theory to help examine the learning taking place in newly formed Children's Services in England. Blackler and Regan (2009) also examined child protection systems in one UK local authority, highlighting the variety of conceptions about the appropriate focus of children's services by 
using Activity Theory as an explanatory framework. Mørck (2011) used Activity Theory to examine issues of empowerment within the social work community in Copenhagen, and Nissen $(2004,2009)$ applied an Activity Theory perspective to an examination of objectification in the same context. It is surprising that Activity Theory has not been more widely utilised in social work research given the obvious applicability of the perspective to a range of issues, as illustrated by this limited list of examples.

Some writers (Letorski, 2004) have suggested that one objection to Activity Theory is its historical link to Marxist ideology. However, this is unlikely to prove a major stumbling block for social work researchers since Marx already commands the status of influential philosopher within the theoretical armoury of the profession. The lack of social work research studies utilising this theoretical perspective is far more likely to be related to a simple lack of awareness within the profession. Perhaps it points to a general lack of activity within the social work community to search within other professional disciplines for new theoretical perspectives that may provide useful heuristic models for social research. Hopefully, a brief account of the history of Activity Theory will address a general lack of familiarity and whet the reader's appetite to investigate this perspective further.

\section{History of Cultural-Historical Activity Theory}

The roots of Activity Theory can be found in the paradigmatic shifts that took place as a response to the industrial revolution during the 19th century, which ushered in ideas about organisms and the environment being both intertwined and in a process of dynamic change (Engeström, 1987). Marx, in particular, put forward the idea that humans master nature through their activity and thereby become creators of the world rather than simply passive subjects shaped by the environment (Giest, 2008). For example, different assessment tools have been developed by academic institutions to assist field educators and these tools in turn shape the way field educators understand their role.

Vygotsky developed Marx's concept of the centrality of activity and the dialectical relationship between humans and the environment as a solution to the problem of how to understand psychological phenomena without simply focusing on the biological or behavioural processes of the individual on the one hand, or the impact of the external environment on the individual on the other (Daniels. 2001). Vygotsky suggested that all activity is mediated in some way by signs or tools and these in turn have a modifying effect on the individual. For example, language is an important tool that mediates between an individual, such as a social worker, and an object, such as a vulnerable client. However, the particular language that the social worker learnt as a child also has an influence on how she thinks about and understands the world. Think of the different world views of Māori and Pakeha social workers that are shaped by language use. This dialectical relationship can be represented in the form of a triangle with the three points corresponding to subject, object and mediating tools or signs, as shown in Figure one.

Leont'ev, a student of Vygotsky, suggested that activity must be analysed as a collective process. He argued that there is a difference but interconnection between the action of an individual and the activity of a group or community. In the classical illustration of this differentiation, Leont'ev (1978, as cited in Daniels, 2001) highlights the different roles of beaters and hunters involved in a tribal hunt. To consider an example from a social work context, 
one might think about the different roles within a child protection assessment team. Within the team are social workers who have frequent contact with children who need protection from abuse, and administrators who have no direct contact with vulnerable children. The tasks of administrators may be quite similar in a whole range of diverse organisational settings, and their objective is focused on maintaining accurate and easily retrievable information. Considered in isolation, administrators do not appear to be engaged in tasks that are focused on the overall goal of protecting children. However, when embedded in the context of a child protection assessment team, it is easy to see how the actions of an administrator become critically important to protecting children from abuse, and social workers would not achieve this goal as effectively without the involvement of administrators. Individual action and group activity are therefore quite distinct although interconnected.

Figure one. (A) Vygotsky's model of the mediated act (stimulus, response and mediated act - X) and (B) its common reformulation (Engeström, 2001).
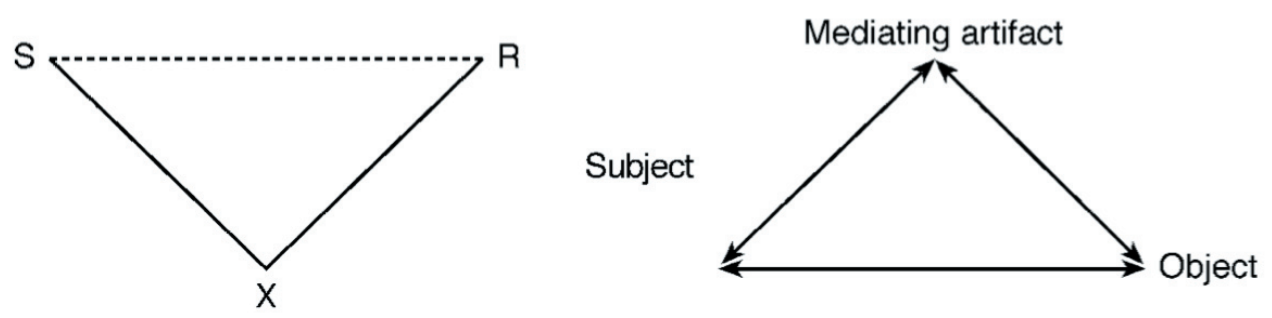

Figure two. Two interacting activity systems as a minimal model for third generation activity theory (Engeström, 2001).

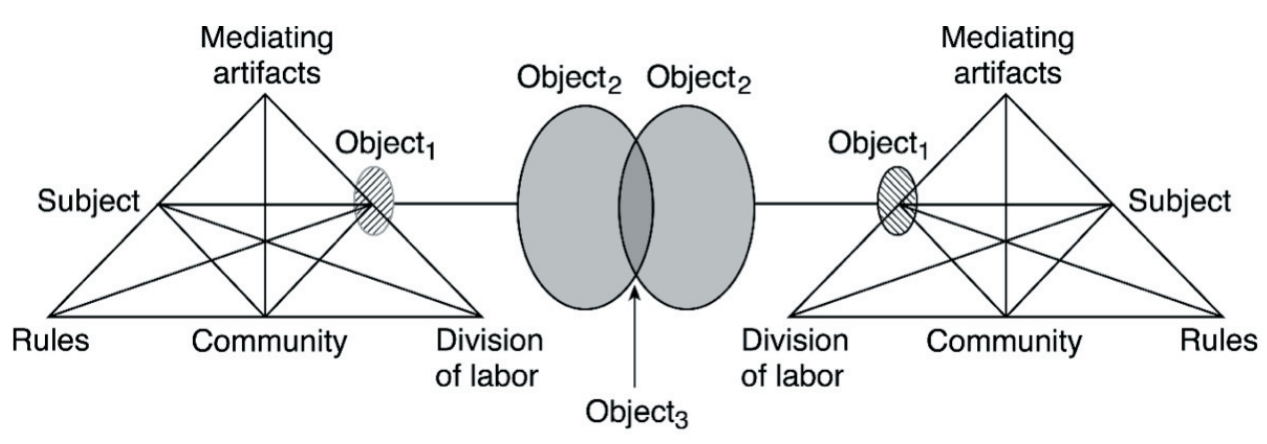

Engeström (1987) has further developed the work of Vygotsky and Leont'ev by suggesting that activity should not be analysed in isolation, but rather as a complex system of interconnected activity. The complexity of activity systems can be seen in the case of field education in that there is a complex relationship between, amongst others, the academic institution, academic staff, social service agency managers, field educators, the professional association and the registration body. Engeström provides an expanded version of Vygotsky's analytical model that incorporates three additional nodes: rules, community and division of labour. 
He argues that all activity is governed by a set of implicit or explicit rules known to the actors, and that decisions must be taken about who will undertake which actions within the activity system to assist towards the overall motivating goal. The subject being focused on is also part of a community of actors who share a similar perspective about the object that is the focus of the activity system. Engeström (2001) argues that all activity systems should be considered in relationship to other closely related systems. The model of two interrelated activity systems shown in Figure two is therefore considered to be the minimal conceptual model to guide researchers in the third generation of Activity Theory. The model is made up of two diagrams that depict the simplest form of an activity system, showing how new objects can be created through the interaction of the two systems.

\section{Key concepts in Cultural-Historical Activity Theory}

Engeström's version of Activity Theory particularly emphasises the importance of contradictions, which he argues are integral to all activity systems and provide the motivation for transformation and change (Engeström, 1987). The idea of contradictions is particularly relevant to field education, which is an activity system that features a number of significant tensions. Contradictions occur at four levels: within the individual nodes of the analytical model, between the nodes, between lower and higher-order activity systems, or between neighbouring activity systems (Engeström, 1987). These contradictions emerge as disturbances evident by deviations in the normal script, disco-ordination in interaction, deviations in the flow of interaction, or disruptions in activities (Murphy \& Rodriguez-Manzanares, 2008). Engeström (1987) suggests that contradictions are characterised by a double bind, a no-win situation experienced within an activity system. If these disturbances are acknowledged and discussed then they act as a catalyst for change and activity can be transformed (Murphy \& Rodriguez-Manzanares, 2008; Engeström, 1987). Identifying and analysing contradictions within an activity system is therefore a helpful method of promoting learning that transforms the nature of the activity system and the way that it works.

This highlights the importance of expansive learning within activity theory. Engeström (2001) suggests that contradictions embedded within activity systems can be aggravated in such a way that individual actors are prompted to begin to innovate and deviate from accepted patterns. In some cases this leads to a collective intentional change effort that evokes new objects and objectives. 'An expansive transformation is accomplished when the object and motive of the activity are reconceptualised to embrace a radically wider horizon of possibilities than in the previous mode of the activity' (Engeström, 2001). This points to the potential for an Activity Theory approach to be used to bring about a transformation in the quality of field education through highlighting contradictions and tensions.

Activity systems are understood as developing and transforming in this way over relatively lengthy periods of time. They can, therefore, only be fully understood by examining the history of the activity system, both in terms of the history of the objects and the tools and signs that have shaped the activity (Engeström, 2001, p.137). For example, consider the history of 'student units' in field education in Aotearoa New Zealand and the lasting influence that this model still exerts on field educators. 


\section{Limitations of Activity Theory}

A full discussion of the limitations of Activity Theory is beyond the scope of this paper. However, certain challenges are important to note in the context of social work and field education. Letorski (2004) has noted that postmodern thinking questions ideas, embedded within Activity Theory, about expansion towards some improved state or utopia, because these concepts are contested. Even if one accepts the possibility of design for developmental improvement, Young (2001) argues that activity theory fails to address the power dynamics within activity systems that may inhibit the questioning and sharing of information required to identify solutions to contradictions. This problem points to the political nature of expansion and change, and Avis (2009) has argued that Engeström's version of Activity Theory in particular often fails to explain how political resistance to expansive learning might be addressed. Indeed, despite the presence of contradictions within activity systems, the motivation for change may not exist (Young, 2001). Certainly within the context of social work generally, and field education specifically, the problems of powerlessness and marginalisation are significant factors that may inhibit learning and change. Whilst it must be acknowledged that Activity Theory does not provide solutions to these dynamics, it does provide a heuristic model for highlighting the contradictions that embody power, demotivation and resistance to change.

\section{Cultural-Historical Activity Theory applied to field education}

Activity Theory is not a grand theory or even a single unified model; the theoretical principles of Activity Theory must be adapted and operationalised within each specific application (Engeström, 1987). An Activity Theory perspective on the challenge of quality and practitioner competence in field education would involve expanding the unit of analysis from the individual field educator and their cognitive or cultural learning. The focus becomes the whole activity system in which field education is located and the interconnection between activity systems, such as the academic institution and the social service agency. Taking this perspective may reveal new insights into the points of conflict and pressures that might be used as a catalyst to promote expansive learning by the field education activity system as whole. This would require researchers to engage with the multiple perspectives of field educators, social service managers, academics, students, the professional association and the registration authority, to understand the historical and current expressions of the activity of field education, and to identify the embedded contradictions. Figure three is a schematic model of the activity of field education, with the potential points of tension highlighted.

Within the activity system of the social services agency providing field education there are a number of contradictions that experience would suggest as possible areas of tension. Firstly, the level of individual motivation of the field educator is likely to have an impact on their choice of methods. A highly motivated field educator is likely to seek out appropriate teaching methods, read relevant material about field education or attend a training course. Significantly, they are likely to actually incorporate this learning into the way in which they work with students. Conversely, an unmotivated field educator may be presented with the same resources and opportunities but fail to integrate them into their practice, leading to a negative impact on the outcomes for students. 


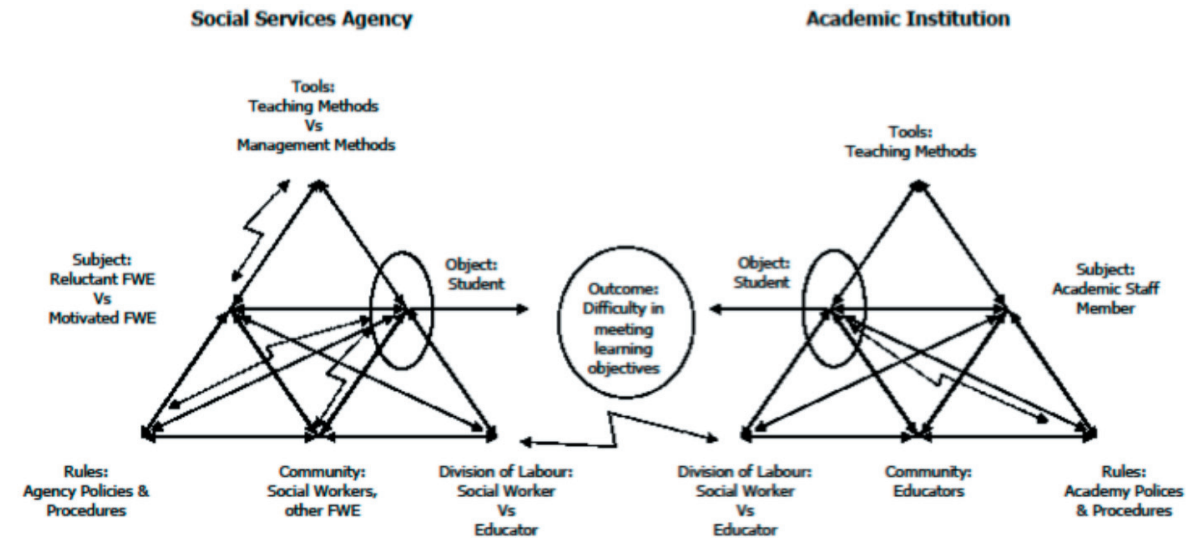

The rules of the social service agency may also impact on the student and methods that the field educator utilises. The agency may be reluctant for audio or video recording of interviews with clients to be used or may not approve of one-way screens, thereby limiting the options for the field educator to directly observe the student's practice. The agency rules may also place expectations on the field educator to prioritise their casework and in the absence of increased resources they may be unable to focus on the teaching input that the student requires. Policies related to professional supervision may also lead the field educator to adopt methods heavily influenced by management rather than pedagogy.

All field educators operate in an environment that brings them into regular contact with other professionals who may have worked with students; not just social workers but also health professionals, allied health professionals, corrections officers or teachers. This community will ideally be involved in supporting the learning of the student but some teams are more open to this approach than others. Some field educators become isolated, whilst colleagues expect them to continue to perform at the same pace as prior to having a student. Significant messages about the best approach to take with students will also be shared that may not be consistent with best pedagogical practice.

Within the activity system of the academic institution there may also be tensions created by the rules for the student. The academic staff will have to ensure that certain tasks are completed by the student regardless of the teaching competence of the field educator. Academic staff are likely to feel some obligation to help the student successfully negotiate a weak placement. This may lead to an approach that focuses on manipulating the expectations so that that student is able to pass their placement even though they may not have received the support they require from the field educator. Addressing the weaknesses of the field educator may also be extremely challenging and the solution may be to simply not use them again rather than try to embark on some professional development process.

This also highlights the potential tension between the two activity systems, particularly in the area of the division of labour. On the one hand, field educators may assume that the 
teaching input is provided by academic staff in the classroom context and their role is more focused on providing an opportunity to undertake practical social work tasks. On the other hand, academic staff may find it difficult to teach and assess certain attitudinal changes and hope these will be magically addressed in the context of the field placement. The division of labour related to assessment is also likely to be a source of tension that can create a contradiction. When field educators lack expertise in assessment, academic staff are likely to become more rigid about the fact that assessment is their responsibility even though they are not in a position to assess effectively without quality observations from the field educator. A lack of clarity on both sides may have a significant impact on outcomes for students.

\section{Conclusion}

Field education appears to be an activity that is characterised by tensions and contradictions and a complex interrelationship between actors in different organisational settings. These tensions and contradictions impact on the approach that field educators take to working with students and their own professional development, which in turn impacts on the quality of outcomes for students. Highlighting the kinds of tensions that have been suggested in this article to the actors involved in the local delivery of field education, may lead to creative energy that can be used to resolve the contradictions and thereby transform and improve the activity of field education. Engeström (2001) has described the use of a 'Boundary Crossing Laboratory' that enables researchers to facilitate these discussions and the creative process. Researchers are therefore not impartial observers but actively involved in the process of development and expansion. Solutions are unique to the individual context, although perhaps suggesting avenues that might be explored in other locations. In this sense, it is less important that the solutions are transferrable and more important that the analytical model and method of finding solutions can be applied in other settings and to other problems. Cultural-Historical Activity Theory, and particularly the analytical tools that have been developed by Engeström and others, offers a useful theoretical framework for resolving the challenges facing social work field education. Specific research studies are required to apply the model and test its efficacy as a heuristic tool, but it certainly has potential to open up exciting avenues for developing our knowledge about field education. As a cross-disciplinary model that has been applied to a range of problems, Activity Theory also has potential for widespread application to other concerns in social work and will hopefully become more widely utilised by the profession.

\section{References}

Avis, J. (2009). Transformation or transformism: Engeström's version of activity theory? Educational Review, 61(2), 151-165.

Bellinger, A. (2010). Studying the landscape: Practice learning for social work reconsidered. Social Work Education, 29(6), 599-615.

Billett, S. (2007). Including the missing subject - Placing the personal within the community. In J. Hughes, N. Jewson, \& L. Unwin (Eds.) Communities of practice - Critical perspectives, pp. 55-67. Abingdon, Oxfordshire, UK: Routledge.

Blackler, F., \& Regan, S. (2009). Intentionality, agency, change: Practice theory and management. Management Learning, 40(2), 161-176.

Daniels, H. (2001). Vygotsky and pedogogy. London, UK: Routledge Falmer.

Daniels, H. (2004). Cultural-Historical Activity Theory and professional learning. International Journal of Disability, Development and Education, 51(2), 185-200.

Edwards, A. (2007). Working collaboratively to build resilience: A CHAT approach. Social Policy and Society, 6(2), 255-264. 
Engeström, Y. (1987). Learning by expanding: An activity theoretical approach to developmental research. Helsinki, Finland: Orienta-Konsultit Oy.

Engeström, Y. (2000). Activity Theory as a framework for analyzing and redesigning work. Ergonomics, 43(7), 960-974.

Engeström, Y. (2001). Expansive learning at work: Toward an activity theoretical reconceptualization. Journal of Education and Work, 14(1), 133-156.

Engeström, Y., \& Miettinen, R. (1999). Introduction. In Y. Engeström, R. Miettinen, \& R-L. Punamaki (Eds.). Perspectives on Activity Theory (pp. 1-16). New York, NY: Cambridge University Press.

Fernandez, E. (1998). Student perceptions of satisfaction with practicum learning. Social Work Education, 17(2), 173-201.

Fernandez, E. (2003). Promoting teaching competence in field education. Women in Welfare Education, 6, 103-129.

Feryok, A. (2009). Activity Theory, imitation and their role in teacher development. Language Teaching Research, 13(3), 279-299.

Fortune, A. \& Abramson, J. (1993). Predictors of satisfaction with field practicum among social work students. The Clinical Supervisor, 11(1), 95-111.

Fortune, A., McCarthy, M. \& Abramson, J. (2001). Student learning processes in field education: Relationship of learning activities to quality of field instruction, satisfaction, and performance among MSW students. Journal of Social Work Education, 37(1), 111-124.

Fuller, A. (2007). Critiquing theories of learning and communities of practice. In J. Hughes, N. Jewson, \& L. Unwin. Communities of practice - Critical perspectives. Abingdon, Oxfordshire, UK: Routledge.

Giest, H. (2008). The formation experiment in the age of hypermedia and distance learning. In B. van Oers, W. Wardekker, E. Elbers, \& R. van der Veer (Eds.). The transformation oflearning: Advances in cultural historical activity theory (pp. 100-126). New York, NY: Cambridge University Press.

Guldberg, K. (2010). Using the lenses of socio-cultural activity theory and communities of practice to guide an empirical study. In L. Dirckinck-Holmfield, V. Hodgson, C. Jones, M. De Last, D. McConnell, \& T. Ryberg (Eds.). Proceedings of the 7th International Conference on Networked Learning (pp.168-175). Lancaster, UK: University of Lancaster.

Knight, C. (1996). A study of MSW and BSW students' perceptions of their field instructors. Journal of Social Work Education, 32(3), 399-414.

Kollias, V., Mamalougos, N., Vamvakoussi, X., Lakkala, M., \& Vosniadou, S. (2005). Teachers' attitudes to and beliefs about web-based collaborative learning environments in the context of an international implementation. Computers and Education, 45(3), 295-315.

Lave, J., \& Wenger, E. (1991). Situated learning - Legitimate peripheral participation. Cambridge, Cambridgeshire, UK: Cambridge University Press.

Leadbetter, J. (2008). Learning in and for interagency working: Making links between practice development and structured reflection. Learning in Health and Social Care, 7(4), 198-208.

Letorski, V., A. (2004) The Activity Approach: Death or rebirth? Journal of Russian and East European Psychology, $42(2), 12-29$

Maidment, J. (2000). Methods used to teach social work students in the field: A research report from New Zealand. Social Work Education, 19(2), 145-154.

Mørck, L. L. (2011). Studying empowerment in a socially and ethnically diverse social work community in Copenhagen, Denmark. ETHOS, 39(1), 115-137.

Murphy, E., \& Rodriguez-Manzanares, M. (2008). Using activity theory and its principles of contradictions to guide research in educational technology. Australasian Journal of Educational Technology, 24(4), 442-457.

Nissen, M. (2004). Wild objectification: Social work as object. Outlines, 1, 73-89.

Nissen, M. (2009). Objectification and prototype. Qualitative Research in Psychology, 6, 67-87.

Ryle, A. (1999) Object relations theory and activity theory: A proposed link by way of the procedural sequence model. In Y. Engeström, R. Miettinen, \& R-L. Punamaki (Eds.). Perspectives on Activity Theory (pp. 407-418). New York, NY: Cambridge University Press.

Shardlow, S. \& Doel, M. (1996). Practice learning and teaching. Basingstoke, Hampshire, UK: Macmillan Press.

Tertiary Education Commission (2009). Social work education in New Zealand. Wellington, New Zealand: Author.

van Oers, B. (2008). Learning and learning theory from a Cultural-Historical Point of view. In B. van Oers, W. Wardekker, E. Elbers, \& R. van der Veer (Eds.). The transformation of learning: Advances in Cultural-Historical Activity Theory (pp. 3-12). New York, NY: Cambridge University Press.

Vayda, E., \& Bogo, M. (1991). A teaching model to unite classroom and field. Journal of Social Work Education, 27(3), 271-278.

Wilson, G., Walsh, T. \& Kirby, M. (2008). Developing practice learning: Student perspectives. Social Work Education, 27(1), 35-50.

Young, M. (2001). Contextualising a new approach to learning: Some comments on Yrjo Engeström's theory of expansive learning. Journal of Education and Social Work, 14(1), 157-161. 